\title{
THE DISTRIBUTION OF THE PERIODICAL CICADA IN NEW ENGLAND IN 1906.
}

In New England the Periodical Cicada (Tibicen septendecim) of 1906, known as brood VIII (Marlatt) is confined to portions of Plymouth and Barnstable counties, Massachusetts. I have attempted to find out, as nearly as possible, the area occupied by this insect in the two counties. The most northern locality seems to be the Manomet Hills, or "Pine Hills" as they are locally called, about five miles southeast of Plymouth. This is the only record I have from Plymouth county. In Barnstable county, it is more widely distributed. Mr. Arthur A. Heald, Supt. of Public Schools, of Wareham, in a letter dated June 27, says:- "At present all that I can speak of with certainty are the towns of Sandwich, Mashpee, Bourne and Falmouth. Mr. Joseph A. Cushman found them very abundant at North Falmouth, June 15; they were also very plentiful at Cataumet and Pocasset. Miss Delia I. Griffin, Curator of the Fairbanks Museum, St. Johnsbury, Vermont, found it in great numbers in the woods near Osterville; this is the most easterly locality from which it has been reported. It made its appearance during the first week in June, the third being the first positive date $I$ have of its emergence.

C. W. Johnson.

\section{ERRATA.}

In Mr. Knab's paper on Deinocerites cancer, published in Psyche, Vol. XIII, No. 4, August, 1906, the following corrections should be made:

p. 97, line 11 from top, after Dyar insert \&.

p. 97 , line 6 from bottom, for usually read unusually. 

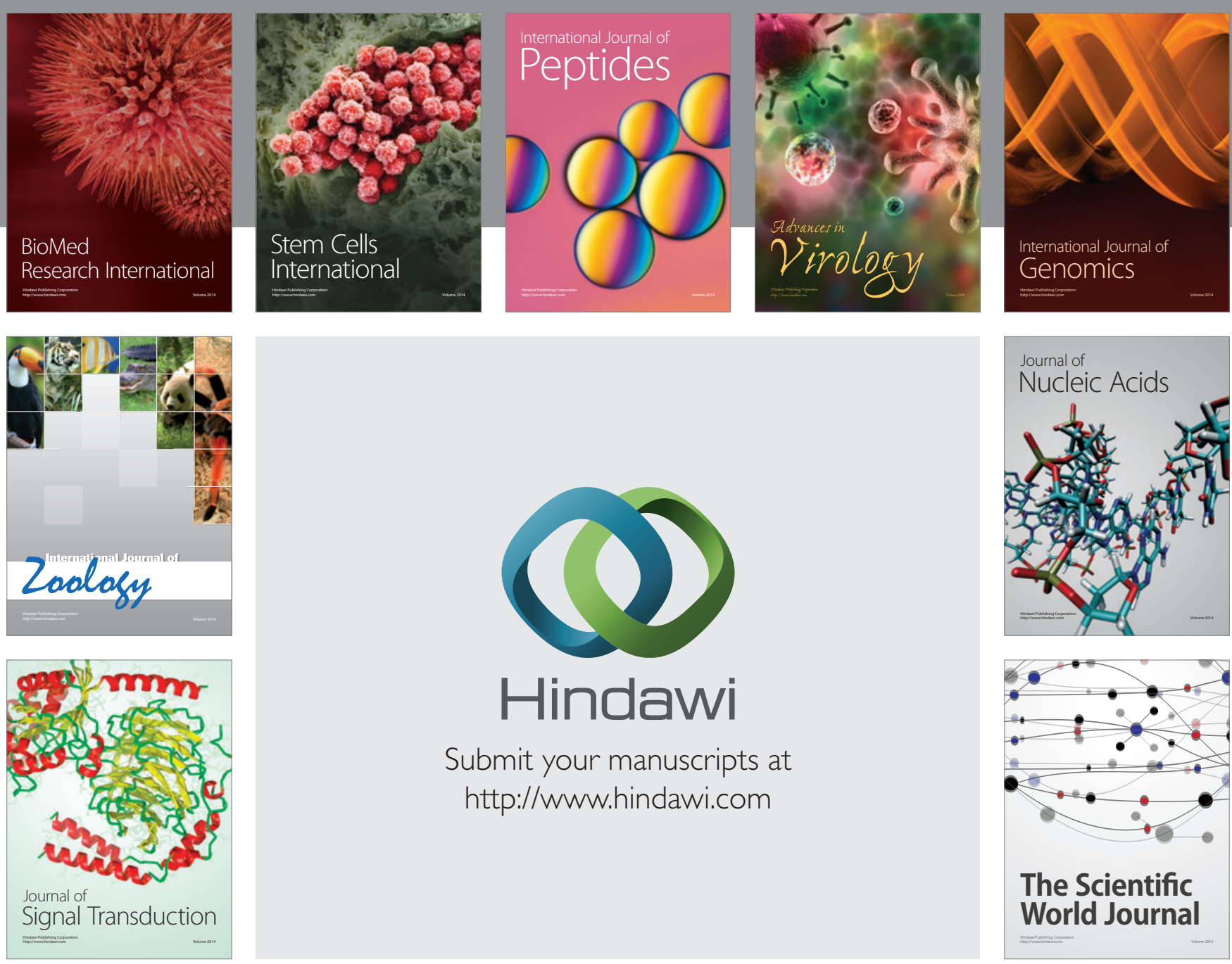

Submit your manuscripts at

http://www.hindawi.com
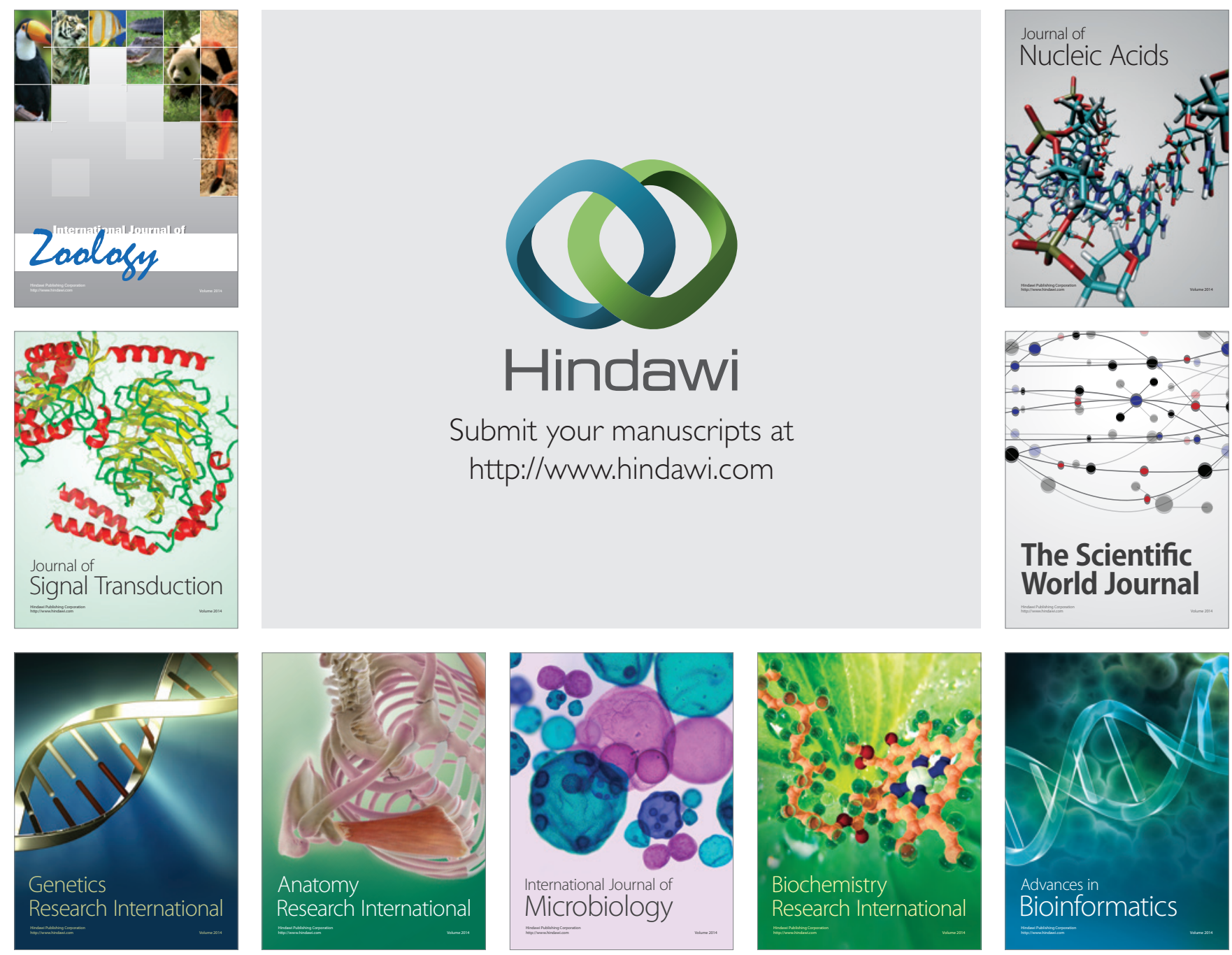

The Scientific World Journal
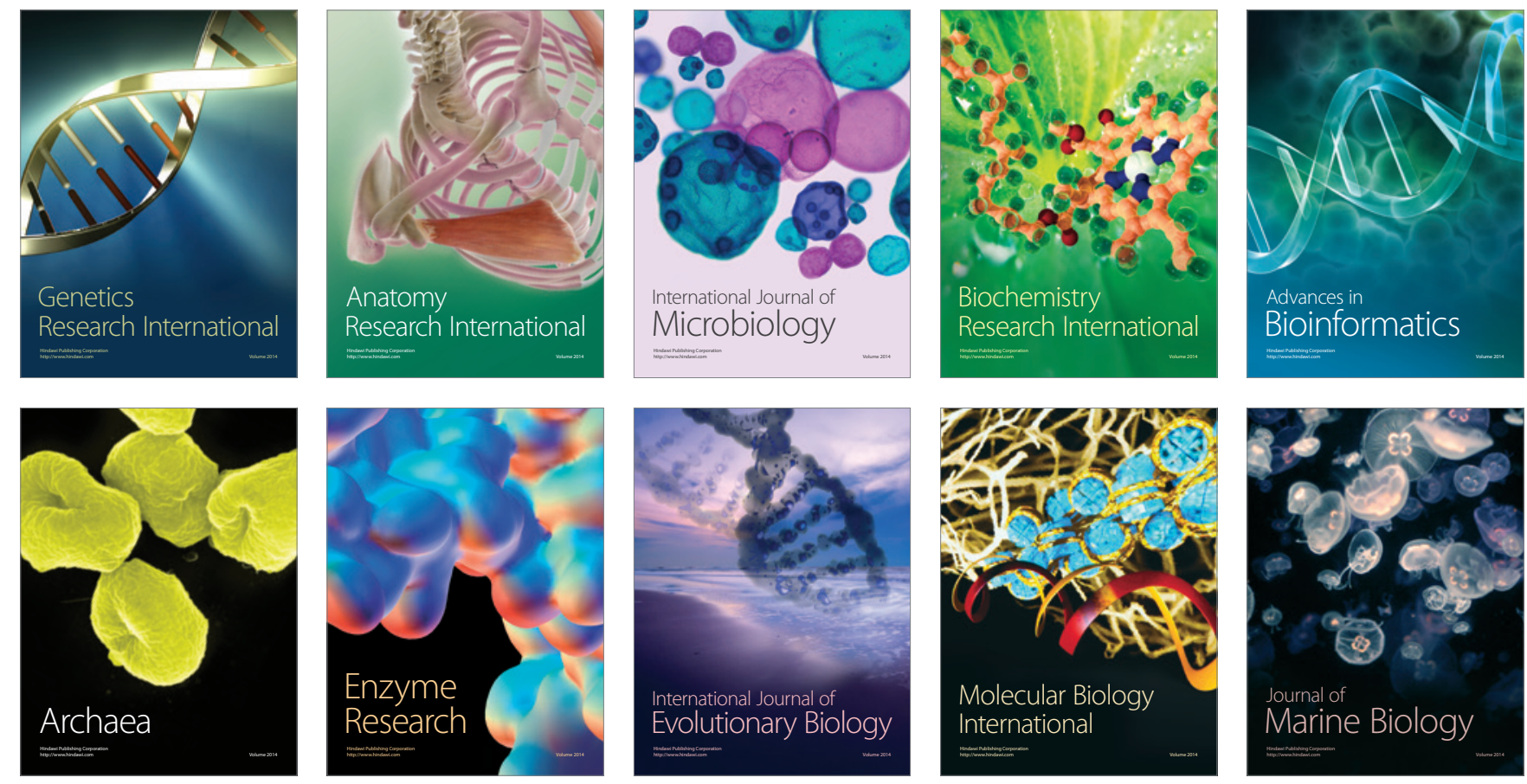